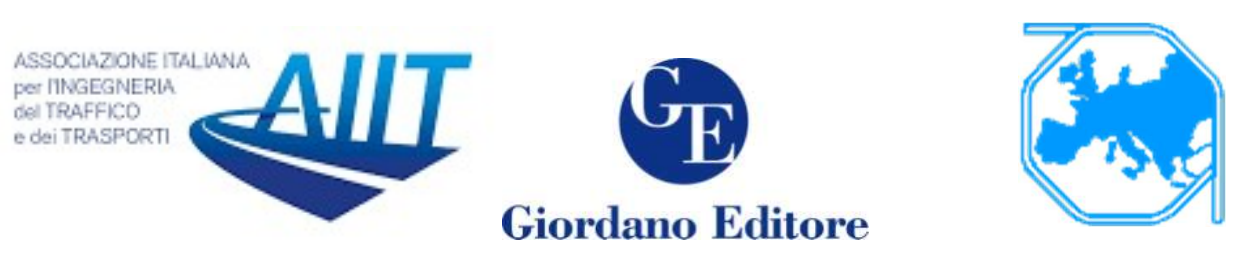

\title{
Fuel consumption optimisation using structural equation modelling and genetic algorithm approach: The case of commercial aviation
}

\author{
Vedant Singh $^{1}$, S. Vaibhav ${ }^{2}$, Virender Singh ${ }^{3}$ \\ ${ }^{1}$ State Project Implémentation Unit (SPIU) - Himachal Pradesh, India- 175018 \\ ${ }^{2}$ Career Point University Hamirpur, Himachal Pradesh, India- 176041 \\ ${ }^{3}$ Himachal Institute of Engineering \& Technology, Kangra, Himachal Pradesh, India- 176223
}

\begin{abstract}
The main aim of this study is to develop a model for minimising fuel consumption in civil aviation. Structural equation modelling (SEM) is utilised for this purpose and the model is developed in terms of various factors that influence fuel consumption in civil aviation. Total 249 questionnaires were sent out to aviation experts to identify the decision variables of strongly correlated dimensions. The results of SEM show four key underlying factors that have a positive effect on both fuel consumption and fuel optimisation. These factors are aircraft design and technology, aviation infrastructure and operation management, socioeconomic measures and the use of alternative fuels. Fuel consumption of commercial transport aircraft was reduced using a genetic algorithm. The results of this study reinforce that fuel consumption optimisation could have a distinctive effect on competitive benefit and structural performance commercial aviation.
\end{abstract}

Keywords: Air Transport; Fuel Consumption Optimization (FCO); Structural Equation Modelling (SEM), Genetic Algorithm (GA)

\section{Introduction}

According to an IPCC (2018) report, our effort should be to limit the temperature rise to $1.5^{\circ} \mathrm{C}$ by 2030 , but commercial air transportation presents a critical challenge. Fuel consumption is an important aspect of air transportation activities that contributes to global warming. In 2010, international aviation consumed 142 million MT of fuel (ICAO, 2016). It is estimated that domestic operations account for $38 \%$ whereas the international procedures account for $62 \%$ of the universal fuel consumption (Singh and Sharma, 2014). Further, the fuel consumption for an aircraft depends on aircraft technology, aircraft weight, occupancy and cruise speed. Chang et al. (2014) concluded that inefficient aircraft activities also lead to more fuel consumption. Available aviation infrastructure and congestion at airports also cause unproductive activities and thus wastage of fuel. Moreover, the growing concepts of long-haul flights and low-cost airlines also rely on aircraft fuel consumption. Therefore, fuel consumption optimisation (FCO) is essential to diminish the direct operating cost of an airline company. 
The research conducted by Hileman et al. (2013), Lawrence (2009), Green (2009), Lee and Mo (2011), Singh (2016), Singh (2018), Singh and Sharma (2016, 2015, 2014) and Singh et al. (2016) explored several important factors that affect the fuel consumption of an aircraft. In addition, genetic algorithms (Antoine and Kroo, 2005; Henderson et al., 2012; Singh 2018; Singh et al. 2016; Wang et al., 2014), system dynamic forming (Sgouridis et al. 2011), simulation modelling (Vespermann and Wald, 2011) as well as structural equation modelling (Chen, 2013; Singh 2016; Singh and Sharma, 2014; Singh et al. 2016) have been employed by various researchers in examining fuel consumption. In the civil aviation industry, two vital gaps in FCO research exist in the literature. Firstly, the adapted models do not provide a dominant separate indicator for FCO like "aircraft technology and design (AT)", "aviation operations and infrastructure (AOI)", "socioeconomic and political area (SEP)", and "the use of alternative fuels and their characteristics (AF)". The correlations of FCO with AT, AOI, SEP, and AF are also neglected. The second gap is the absence of robust optimisation techniques for fuel consumption. This study addresses these central gaps using a single integrated SEM-GA model, where SEM is followed by genetic algorithm (GA) based optimisation.

In SEM, iterative estimations are utilised for solving structural equations, for which initial estimates of the unknown parameters are acquired to calculate implicit variance and covariances. This procedure terminates when there is a difference in the experiential and implicit covariance matrices are within an acceptable range. Mclntosh and Gonzalez (1994) also concluded that the optimisation routine framework behaves well under a given realistic set of calculations and preliminary conditions for an iterative estimate, and procedures used for iterative fitting will normally give the equivalent results in data sets in which the covariance matrix is not singular. Therefore, the optimisation of the decision variables of FCO in air transportation industry has been employed after validation of the SEM model.

The paper is systematised as follows: The persuading factors that affect FCO are explored with an integrated model of FCO in Section 2, which also includes how this influence is exerted. The research methodology is also discussed in Section 2, whereas Section 3 deals with testing of data and presenting the results of the study. The discussion and conclusions are presented in Section 4.

\section{Background}

\subsection{Hypotheses development}

\subsubsection{Aircraft technology and design (AT)}

Aircraft technology (AT), which includes the type of engine, aerodynamics, Mach number and design, is an important factor that affects aircraft fuel consumption. Improvements in fuel efficiency also helps reduce aviation emissions. For a specific distance and Mach number, the fuel burn discharge depends on the aircraft's weight, specific fuel consumption and its lift over drag (L/D) ratio (Kar, 2010). Findings from the literature indicate that fuel efficiency of an aircraft also depends on engine and airframe design. Also, an improvement in engine efficiency and reducing the aircraft's drag and weight lead to less fuel burn (Henderson et al., 2012). Lee (2010) and Green (2009) also explored design of the engine and its aerodynamic efficiency. Lee et al. (2001) and Babikian (2002) studied improvement in engine, aerodynamics and aircraft structures to reduce fuel burn and suggested the factors such as specific fuel consumption, $\mathrm{L} / \mathrm{D}$, and structural efficiency should be explored. Moreover, Sgouridis et al. (2011) suggested to 
improve engine design and aerodynamics and use of lightweight material for aviation FCO. The technological options for emission reduction include aerodynamic changes, weight reduction, more fuel-efficient engine and increased operational efficiency (Lee et al., 2010). This indicates that the technology used and the design of an aircraft positively contribute towards FCO. Consequently, we theorise that: FCO.

H1: There is a positive relationship between aircraft technology and design and

\subsubsection{Aviation operations and infrastructure (AOI)}

An aircraft consumes a huge quantity of fuel throughout its flight and the fuel requirement depends on numerous factors (Miller et al., 2001). Airline companies adopt various strategies for proper operations planning and thus controls factors such as payload, maintenance and scheduled overhauling, flight planning and fuel hedging that considerably impact fuel burning. Literature indicates that aviation operations significantly affect FCO and a few findings are mentioned here. Sgouridis et al. (2011) suggested fuel ferrying practices, payload reduction, cruise speed reduction, optimised ascent and descent paths, optimum cruise level operation continuous descent, optimised land activities and ground path, minimised queuing and use of tow-tugs for taxiing for operational efficiency.

Also, aviation infrastructure plays a role in fuel burn. Airport mobbing and inappropriate air traffic administration increase fuel burn. Improving the infrastructure can reduce fuel burn. Better route designs, airport flexibilities in handling aircraft without delays and improved air traffic management can be viewed as major contributors to fuel saving (Babikian, 2002). Sgouridis et al. (2011) explored the air traffic management and airport design as a major option to reduce aircraft emissions. Senzig et al. (2009) revealed that aviation processes and infrastructure have a substantial effect on FCO. Another hypothesis, thus, is generated as follows.

H2: There is a positive relationship between aviation infrastructure and operation (AOI) and FCO.

\subsubsection{Socioeconomic and policy measures (SEP)}

The aviation industry helps to connect communities, traditions and businesses across the world. It creates social benefits in terms of generating jobs and provides other economic advantages such as international trade and tourism. SEP factors are related to market-based measure, emission trading, demand shift, and voluntary measures, etc. If these factors are successfully handled, a significant fuel reduction can be achieved. Lee and Mo (2011) explored social and economic factors like fuel cost and ticket prices and social pressure to reduce consumption for aircraft fuel efficiency improvement. Simões and Schaeffer (2005) studied levies, surtaxes and surcharges on the fuel, inter-mode transport substitution, higher occupancy rates and specific regulations for emission reduction. Sgouridis et al. (2011) explored the demand shift and market-based measures for emission reduction. Yamaguchi (2010) discussed voluntary plans and Hihara (2011) highlighted market-based measure for fuel burn reduction. Brueckner and Zhang (2010) studied airline emission charges and predicted that emission charges increase the fare, reduce flight frequency, increase the load factor, and raise aircraft fuel efficiency. The third hypothesis based on the above analysis is as follows:

H3: There is a progressive relationship between socioeconomic and political issues (SEP) and FCO. 


\subsubsection{Alternate fuels and fuel properties $(A F)$}

The growth of aviation industry requires looking for alternative fuels for fuel security and environmental concerns. FCO is also governed by the usage of alternate fuels and their characteristics, which can alleviate fuel rate variations and lessen the dependency on crude oil. Hydrogen, ethanol and synthetic fuels are some options to consider. Agarwal (2010) explored fuel alternatives and their properties such as energy content, freezing point, thermal stability, contaminants, viscosity, etc. for fuel burn reductions. Janic (2010) suggested using hydrogen to mitigate emissions and highlighted its properties: specific energy, specific density, energy density, and boiling point, etc. Nojoumi et al. (2009) also highlighted hydrogen as a viable fuel alternative with reduced environmental impact and high energy content. Corporan et al. (2011) explored non-petroleum alternative fuels derived from animal fats, natural gas, coal, etc. and studied their properties such as thermal stability, density and combustion emission.

The best alternative fuel is one that exhibits better properties (thermal, chemical and physical) and is well-matched with the current aircraft and fuel production technology. Alternative fuels and their properties are strongly associated with FCO. Therefore, the hypothesis is:

H4: There is a positive relationship between alternative fuels and fuel properties $(A F)$ and $F C O$.

Aircraft technology (AT), aviation infrastructure and operations (AOI), socioeconomic and policy measures (SEP), alternative fuels (AF) have significant direct effect on FCO. The conceptual model is proposed for FCO in Figure 1, which shows the interrelationship between these factors and FCO. These four (AT, AOI, SEP and AF) are the predictor variables while FCO is taken as the dependent variable. H1, H2, H3 and H4 are the four path hypotheses and every trail signifies a causal correlation with the way of effect, either positive $(+)$ or negative $(-)$.

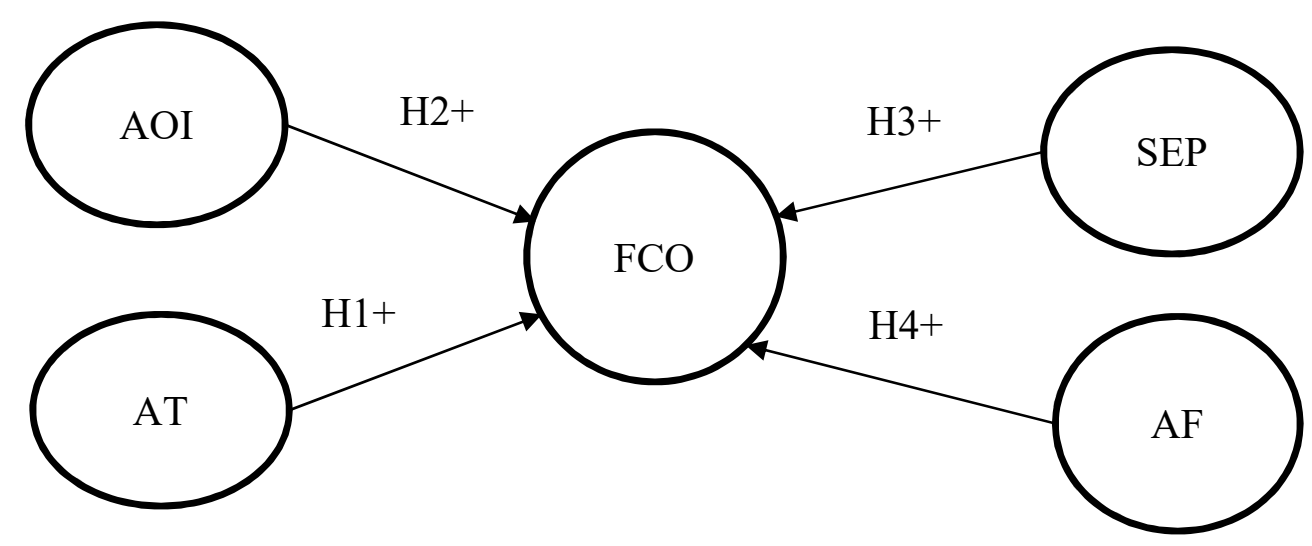

Figure 1: Proposed model of FCO

\subsection{Research methodology}

The analysis consists of two phases. In the first phase, a statistically significant model for FCO is developed. Data was collected through both person- and self- administered questionnaires using a quantitative, survey-based methodology. This method is significant because underlying associations among the primary theoretical constructs 
need to be investigated. A skilled interviewer was present for person-administered questionnaire. The main advantage of using person-administered survey is that additional elucidation about the questions can be offered. However, the benefit of using selfadministered analysis in this investigation was getting an easy access to the senior specialists of the organisations. The survey had two components. The first component provided the demographic information (gender, work experience, type of administration, job details, etc.). The second component was a five-point Likert scale ranging from 1 (strongly disagree) to $5=$ (strongly agree).

AT was measured with eight items, AOI with ten items, SEP with six items, AF with five items and FCO with one item. The scale items used in this study are reproduced in Appendix A. To validate the survey, a pilot study was conducted. The questionnaires were sent with a cover letter stating the purpose of research to different personnel of the aviation sector. The questionnaires were dispensed to 707 respondents and 275 responses were collected with the response rate of $39 \%$. Out of these 275 responses, 26 questionnaires were eliminated because of missing data, leaving the valid sample of 249 responses.

In the second phase, decision variables of two strongly correlated dimensions (as reported in the SEM model) were optimised using GA. GA can solve multi-dimensional, large optimisation non-parametric, non-differential and discontinuous problems. A MATLAB program with GA techniques was developed for the minimisation of fuel consumption.

\subsubsection{Data analysis methods}

First, exploratory factor analysis (EFA) was used to analyse the relationship of the factors based on robust association (Lu et al., 2007). EFA allows items to be correlated to any factor based on observed responses (Singh and Sharma, 2016; Worthington and Whittaker 2006). In second step, CFA was selected to specify and estimate the hypothetical model (Hair et al. 2010). Numerous investigators have recommended using CFA with a manifold sign to check the unidimensionality. It consigns to the fact of solitary constructs underlying a group of measures (Anderson and Gerbing, 1988). CFA overcomes the constraints of EFA, which examines only the base theories. In the SEM analysis, CFA sets out with a hypothesised quantity model and then the model is accepted or rejected based on model fit and interpretations. In third step, SEM was used to develop measurable models that shows the associations between various idle factors. It watches interconnected connections among different dependent on and independent builds simultaneously (Hair et al. 2010).

\subsubsection{Structural equation modelling and optimisation}

After the validation of structural equation model, the optimisation of the model's decision variables was performed. There are some reasons for performing optimisation after validation. In SEM, solutions to structural equations are typically obtained through iterative estimation. Initial estimates of the unknown parameters in structural equations are obtained and a set of implied variances and covariances is computed using derivations similar to those presented in structural and measurement equations as in the case of any SEM (Singh and Sharma, 2016). The implied covariance matrix is then compared with the original covariance matrix. Based on the differences between these two matrices, parameter estimates are modified using iterative fitting techniques. This data fitting procedure finishes when the differences between the observed and the implied covariance 
matrices are in an acceptable range. Also, according to Mclntosh and Gonzalez (1994), the optimisation routines framework behaves well under a reasonable set of equations and initial conditions for iterative estimation; the methods used for iterative fitting will typically give the same results in data sets in which the covariance matrix is not singular. deviations in the final solution are likely when the numbers of known and unknown parameters are close to being equal or there is a singularity in the data set. Therefore, the optimisation of decision variables of fuel consumption in air transport has been employed after validation of SEM model.

\subsubsection{Problem modelling using SEM}

The variables identified from the structural equation model were used for fuel consumption modelling and optimisation. We study the variables AT and AOI, which are chosen for developing the fuel consumption modelling and optimisation framework. The main reason of choosing AT and AOI is that the structural equation model shows the highest correlation between ATD and AOI. The high correlation between the AT and AOI with FCO indicates a strong relationship between the variables (Mclntosh and Gonzalez, 1994). Variables AFP and SEP are not studied here. In case of AFP, selection and availability are the two big concerns for their consideration. Also, SEP was neglected to make the optimisation problem simple because it is very difficult to express SEP in terms of physical quantity. So, after selecting 22 decision variables of AT and AOI, GA was chosen as an optimisation tool for FCO. Eight more decision variables, part of the initial informational framework and in the later stages extracted from AT and AOI, were also included. But, for the simplification of optimisation problem, they were considered in the optimisation process. Singh (2018) and Lee et al. (2001) highlighted the fuel consumption relationship with stage length to realise the influence of technology and operability on aircraft fuel economy, which is given by Equation 1:

$$
\begin{aligned}
& \text { FuelConsumption }\left[\frac{\text { gal }}{\text { ASM }}\right]=\left(\frac{W_{f}}{\text { Seats }}\right) * g * \frac{s f c}{V} *\left(\frac{L}{D}\right) *[\operatorname{I} / \operatorname{In}(1+ \\
& \left.\left.\left(W_{\text {pay }}+W_{\text {str }}+W_{\text {res }}\right) *\left(\frac{100}{100+42707 * R^{-0.933}}\right)\right)\right]
\end{aligned}
$$

where $W_{f}$ is fuel weight, seats is the passengers, $s f c$ is specific fuel consumption, $v$ is flight speed, $L / D$ is lift-over-drag ratio, $g$ is acceleration due to gravity, $W_{\text {pay }}$ is the payload weight, $W_{\text {str }}$ is the structural weight, $W_{\text {res }}$ is the reverse fuel weight and $R$ is the stage length. that is maximisation and minimisation of take-off weight (Wto) of an aircraft. $S f c$, $L / D$ and $v$ is kept constant and highest take-off load has been minimised.

To show how an aircraft fuel consumption problem can be solved using GA, a preliminary maximum take-off weight $\left(W_{t o}\right)$ estimation problem was implemented using a controlled quantity of fuel consumption variables and $W_{t o}$ as the goal function. This equation expresses the aircraft $W_{t o}$, given the crew weight, payload, fuel weight fraction and empty weight fraction of the aircraft. The maximum take-off weight equation (2) is given by Sadraey (2012):

$$
W_{t o}=\frac{\left(W_{\text {crew }}+W_{\text {pay }}\right)}{\left(1-\frac{W_{f}}{W_{t o}}-\frac{W_{e}}{W_{t o}}\right)}
$$

where, $W_{\text {crew }}$ is the weight of the crew, $W_{\text {pay }}$ is the payload, $W_{f} / W_{\text {to }}$ is the fuel weight fraction and $W_{e} / W_{t o}$ is the empty weight fraction. Our main purpose is to reduce the aircraft highest take-off weight and thus to find the minimum value of fuel consumption 
function.

\subsubsection{Genetic algorithms as an optimisation tool}

GA is a group of broad purpose search methods, which is exactingly suitable for compound optimisation problem (Chaudhry and Ahmed, 2014). GAs mainly imitates the selection and endurance of the fittest (Kachitvichyanukul, 2012). GA starts by initialising a populace of solution. GA can, through replicated application of genetic operators (i.e., assortment, mutation and crossover), to combine those parts of a solution required to form a best universal solution (Binitha and Sathya, 2012).

\subsubsection{Implementation of a $G A$}

This study applies GA to minimise maximum take-off weight of an aircraft (Kundu, 2010; Raymer, 1999; Sadraey, 2012). A MATLAB program was developed to implement a GA that can handle 22 dimensions and three constraints. The program comprises of the main GA techniques with suitable GA parameters for better performance, such as elitism. The fitness task value is passed as only one cell value to the GA component to estimate maximum take-off weight. The developed model follows a fixed path and the configuration of the aircraft (Airbus A320-200) was taken from Singh (2018). The average aircraft cruise range and fuel fractions for taxi-take off, climb, decline, landing as well as cruise Mach number were permanent and executed into the program. As shown in Figure 2, the GA evaluates the key design variables based on aircraft load and air travel performance equations.

\subsubsection{Initialisation}

The algorithm is initialised by generating the first population including the number of individual arrays. Each configuration is characterised by a "chromosome" consisting of a string of "genes" arbitrarily initialised on account of autonomous design variables.

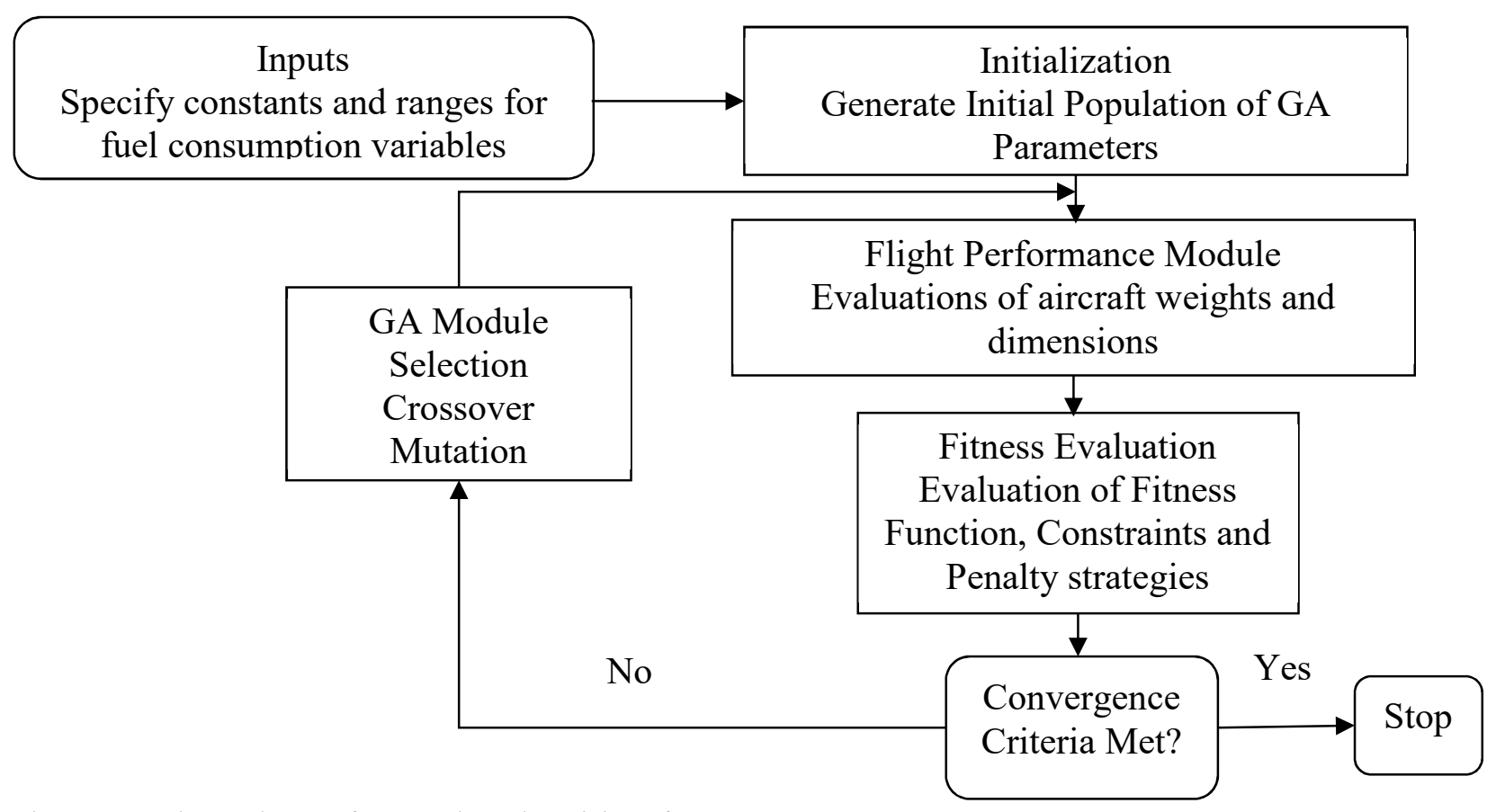

Figure 2: Flow chart of Genetic Algorithm for FCO 


\subsubsection{Fitness and penalising strategies}

Based on the design variable values, each solution was evaluated via fitness function, which imposes penalties if critical constraints are overridden, and was assigned a fitness value. This fitness value was used to evaluate solutions through a selection process. The foremost difficulty in relating GA to FCO is how to handle the constraints. Constraints force the solution by penalising the fitness if they are overridden. This causes excessive reduction of information available for successive generations to draw on, thus improving the GA performance (Gen and Cheng, 1996). We employed a common and efficient penalty strategy in this study.

\subsubsection{Selection process and inverse scheme}

In this algorithm, a fitness-proportionate selection called roulette wheel selection was used. This is one of the most general forms employed in GA as it consistently generates elevated fitness solutions. It allocates the probabilities of a selection that depends on fitness beliefs and the inverse scheme to level fitness and preserves the discrepancy between fitness values. As GAs refine via maximisation, the inverse pattern was implemented to change the GA process to a minimisation. "The result of inverting a big number into a small number" is the logic behind implementing this scheme (Camp et al., 1998).

\subsubsection{Crossover operator}

The current study utilises a uniform crossover by using GA. In a uniform crossover, every gene of the progeny is generated by reproducing the resultant gene from any one parent according to an indiscriminate dual crossover mask of the same length as chromosomes (Singh, 2018; Sivanandam and Deepa, 2007).

\subsubsection{Mutation operator}

The mutation operator helps in creating "chromosomes" through indiscriminate adjustments and thus allows the GA to explore other solutions than the optimal ones (Sivanandam and Deepa, 2007). In the MATLAB program, the vibrant possibility of mutation is used to enhance mutation rates at the closing stages of population.

\subsubsection{Elitism and termination}

An elitism operator in a GA is used to prevent the loss of the best chromosomes by copying the most excellent solution from the previous generation into the new generation. The speed and best fitness for a GA increase through elitism (Deb et al., 2002). The program is terminated when the consecutive iterations do not generate noteworthy better results following the lowest number of generations and the fitness value of the best solution in the generation becomes constant at the maximum.

\section{Data analysis and results}

\subsection{Data screening and normality}

Missing data occur when no data value of the variables is available for analysis (Hair et al., 2010). It is rare to acquire data sets without some omission (Coakes and Steed, 2009). Screening of variables in SPSS using probability sampling led to 28 responses to be discarded due to missing data, that was ignorable since probability sampling permits an analysis of the omitted data that facilitates elimination of observations in random and omitted data (Hair et al., 2010). Furthermore, there were seven responses which had 
missing data for less than $1 \%$. The missing data was restored with the variable mean responses for each parameter. After restoring omitted data with variable means, the measured data was estimated to estimate normality of the distribution. The skewness and kurtosis values were checked for normality and these values were found less than \pm 1 (Kline, 2012), which indicated no variation from data normality.

\subsection{Respondent demographics}

The participants' gender, work experience, education level, type of organisation and position are shown in Table 1 . Table 1 reveals the majority of the respondents were male $(89 \%)$ and the female participants were $11 \%$. Results in Table 1 predicted that the majority i.e. $42 \%$ of respondents as having the working experience between $7-14$ years in the aviation sector. The second largest-number (33\%) of participants was having experience between 14-24 years. In addition, most of the respondents in this survey were having a Doctorate $(47 \%)$ followed by postgraduate qualifications $(41 \%)$. Also, Table 1 shows that the greater number of the respondents were from academic organizations $(46 \%)$ followed by aviation organizations (34\%). Moreover, most of the participants in this survey were academicians related to aviation field $(46 \%)$ followed by research scientists (20\%), directors (19\%), and managers (11\%).

Table 1: Sample demographic of FCO study

\begin{tabular}{llll}
\hline Variable & Category & Frequency & Percentage (\%) \\
\hline Gender & Male & 222 & 89 \\
& Female & 27 & 11 \\
Working & $7-14$ & 105 & 42 \\
experience & $15-24$ & 83 & 33 \\
related to the & $25-50$ & 61 & 24 \\
aviation field & & & \\
(years) & & 117 & 47 \\
Education level & Doctorate & 101 & 41 \\
& Post-graduation & 31 & 12 \\
Type of & Graduation & 115 & 46 \\
organizations & Academics & & \\
& Aviation & 74 & 34 \\
& Research \& & 49 & 20 \\
Position in an & development & & 46 \\
organization & Professors & 115 & \\
& Research scientists & 49 & 20 \\
& Directors & 46 & 19 \\
& Managers & 28 & 4 \\
\hline
\end{tabular}

\subsection{Exploratory factor analysis}

The four FCO constructs were subjected to EFA in SPSS (20.0) using principle component analysis (PCA) with varimax-rotation carried on four FCO factors to refine the parameters underlying each factor. The EFA of 29 units were filled into the four FCO factors (AT, 8 variables; AOI, 10 variables; SEP, 6 variables; AF 5 variables). The result 
of EFA and reliability analysis is shown in Table 2, which also shows the results of Kaiser-Meyer-Olkin (KMO) and Bartlett test of sphericity. KMO test was applied to check the suitability of survey data for factor analysis (FA) and describe the relation of limited correlation to the sum of the squared correlation (Singh and Sharma, 2014; Stewart, 1981; Worthington and Whittaker, 2006). KMO value 0.60 and greater is needed for better FA (Singh and Sharma, 2016). The KMO measure of sampling adequacy results for constructs $\mathrm{AT}=0.903, \mathrm{AOI}=0.896, \mathrm{SEP}=0.822$, and $\mathrm{AF}=0.843$, which surpassed the minimum limit 0.60 for all constructs. While the Bartlett test of sphericity provided the critical values for all the factors (Table 2). As all the values were within limits, the sample data was suitable for factor analysis.

Corrected item-total correlations (CITC) were employed to examine the uniformity of the run with the mean response of others (Churchill, 1979). Items with CITC and factor loadings $<0.5$ were removed (Hair et al., 2010). The variables ATA, ATH, AOIC, AOID, AOII, SEPB, SEPF and AFE had CITC and factor scores $<0.5$ were deleted from the model. Also, Table 3 shows the Eigenvalues and the percentage of the variance of each factor, which were well within the limits as suggested by Singh and Sharma (2014).

Cronbach's alpha was used to check the reliability of the factors (Cortina, 1993). The reliability coefficient $(\alpha)$ of each of the constructs was well above the minimum level of 0.70 (AT, 6 variables, $\alpha=0.933$; AOI, 7 variables, $\alpha=0.917$; SEP, 4 variables, $\alpha=0.859$; $\mathrm{AF}, 4$ variables, $\alpha=0.843$ ) (Hair et al., 2010).

\subsection{Confirmatory factor analysis}

CFA is the next step after EFA, aimed to analyse the hypothesised model using the sample of 249 respondents. The measurement model was checked for adequacy by CFA, using AMOS 24. The items AOIA, AOIG, SEPD, AFB, and AFC had the standardised factor loadings below 0.50 as shown in Table 3. So, they were removed from the analysis as suggested by Singh and Sharma (2016).

Convergent validity (CV) was checked by examining the $p$-values through $t$-values. A $t$-value $>1.96$ or $<1.96$ explains statistical significance (Byrne, 2013; Singh and Sharma, 2014). Here, all $t$-values were at the significance level. CV can also be inspected by the average variance extracted (AVE), which ranged from 0.505 to 0.612 (Table 4), so all values were higher than the suggested 0.50 levels (Fornell and Larcker, 1981), indicating that the $\mathrm{CV}$ of the measurement model is accepted.

The reliability of specific observed items was checked by item reliability $\mathrm{R}^{2}$ (Bollen, 1989), which are greater than the lower limit of 0.50 (Table 4). Besides, the composite reliability was estimated by the formula of Fornell and Larcker (1981) as shown in Table 4. All reliability values exceeded the critical value of 0.70 suggested by Hair et al. (2010).

Discriminate validity was investigated by differentiating the square of correlation among each pair of factors with an AVE and the largest correlation was observed among AT and AOI (0.500; Table 4). This is critically less than their individual AVEs. Therefore, the model has discriminate validity.

Nomological validity was estimated by analysing whether a construct belongs to all other constructs within a system (Singh and Sharma, 2016). The nomological validity of the model was estimated by using factor correlations (Tables $4-5$ ). The results in Tables 4 and 5 indicate that all correlations are significant, with the anomaly of SEP $<->$ AF $(t-$ value $=1.406 ; p=0.160$ ), which was positive but not significant. Generally, the correlations were compatible with the theory and thus provided the nomological validity (Hair et al., 2010). 
Table 2: Results of exploratory factor analysis (EFA) of FCO

\begin{tabular}{|c|c|c|c|c|c|c|}
\hline $\begin{array}{l}\text { Constructs and } \\
\text { variables of ERP }\end{array}$ & $\begin{array}{l}\text { Factor } \\
\text { loadings }\end{array}$ & CITC & $\begin{array}{l}\text { Eigen- } \\
\text { values }\end{array}$ & $\begin{array}{l}\% \text { of } \\
\text { variance } \\
\text { explained }\end{array}$ & KMO & $\begin{array}{l}\text { Cronbach's } \\
\alpha\end{array}$ \\
\hline Aircraft technology & & & 3.46 & 75.00 & 0.903 & 0.933 \\
\hline \multicolumn{7}{|l|}{$\&$ design (AT) } \\
\hline ATE & 0.882 & 0.816 & & & & \\
\hline ATG & 0.875 & 0.821 & & & & \\
\hline ATD & 0.872 & 0.820 & & & & \\
\hline ATB & 0.871 & 0.801 & & & & \\
\hline ATC & 0.848 & 0.772 & & & & \\
\hline ATF & 0.846 & 0.786 & & & & \\
\hline \multicolumn{7}{|c|}{ Bartlett test: $\chi^{2}=1185.880, \mathrm{df}=15, \mathrm{p}=0.000$} \\
\hline Aviation operations & & & 3.90 & 67.36 & 0.896 & 0.917 \\
\hline \multicolumn{7}{|l|}{$\begin{array}{l}\& \text { infrastructure } \\
(\mathrm{AOI})\end{array}$} \\
\hline AOIA & 0.734 & 0.665 & & & & \\
\hline AOIB & 0.870 & 0.817 & & & & \\
\hline $\mathrm{AOIH}$ & 0.797 & 0.724 & & & & \\
\hline AOIJ & 0.832 & 0.762 & & & & \\
\hline AOIE & 0.853 & 0.775 & & & & \\
\hline AOIF & 0.878 & 0.810 & & & & \\
\hline $\mathrm{AOIG}$ & 0.747 & 0.663 & & & & \\
\hline \multicolumn{7}{|c|}{ Bartlett test: $\chi^{2}=1181.326, \mathrm{df}=21, \mathrm{p}=0.000$} \\
\hline $\begin{array}{l}\text { Socio-economic \& } \\
\text { political (SEP) }\end{array}$ & & & 3.07 & 70.57 & 0.822 & 0.859 \\
\hline SEPA & 0.839 & 0.701 & & & & \\
\hline SEPE & 0.826 & 0.720 & & & & \\
\hline SEPC & 0.847 & 0.702 & & & & \\
\hline SEPD & 0.845 & 0.703 & & & & \\
\hline \multicolumn{7}{|c|}{ Bartlett test: $\chi^{2}=483.613, \mathrm{df}=6, \mathrm{p}=0.000$} \\
\hline \multicolumn{7}{|l|}{ fuel properties (AF) } \\
\hline AFA & 0.899 & 0.828 & & & & \\
\hline AFB & 0.933 & 0.865 & & & & \\
\hline AFC & 0.951 & 0.907 & & & & \\
\hline AFD & 0.885 & 0.805 & & & & \\
\hline \multicolumn{7}{|c|}{ Bartlett test: $\chi^{2}=905.963, \mathrm{df}=6, \mathrm{p}=0.000$} \\
\hline Note: See Appendix & for mean & g of eac & $\mathrm{h}$ varia & & & \\
\hline
\end{tabular}

Table 3: Confirmatory factor analysis (CFA) results of FCO

\begin{tabular}{llllll}
$\begin{array}{l}\text { Constructs and } \\
\text { variables of ERP }\end{array}$ & $\begin{array}{l}\text { Unstandardized } \\
\text { factor loadings }\end{array}$ & $\begin{array}{l}\text { Standardized } \\
\text { factor } \\
\text { loadings }\end{array}$ & $\begin{array}{l}\text { Standard } \\
\text { error }\end{array}$ & $\begin{array}{l}\mathrm{t}- \\
\text { values }\end{array}$ & $\begin{array}{l}\mathrm{R}^{2} \text { (Item- } \\
\text { reliability) }\end{array}$ \\
\hline
\end{tabular}

Aircraft technology and design (AT)

$\begin{array}{llllll}\text { ATE } & 1.000 & 0.831 & f & - & 0.691 \\ \text { ATF } & 0.828 & 0.767 & 0.054 & 15.31 & 0.588\end{array}$




$\begin{array}{llllll}\text { ATG } & 0.881 & 0.797 & 0.052 & 16.91 & 0.636 \\ \text { ATC } & 0.966 & 0.816 & 0.066 & 14.63 & 0.666 \\ \text { ATD } & 0.749 & 0.763 & 0.065 & 13.02 & 0.582 \\ \text { ATB } & 1.025 & 0.860 & 0.118 & 15.87 & 0.740 \\ \text { Aviation operations } & & & & & \\ \text { and infrastructure } & & & & & \\ \text { (AOI) } & 1.000 & 0.818 & \mathrm{f} & - & 0.670 \\ \text { AOIF } & 0.956 & 0.781 & 0.049 & 19.34 & 0.610 \\ \text { AOIE } & 0.964 & 0.824 & 0.068 & 14.26 & 0.674 \\ \text { AOIB } & 0.976 & 0.846 & 0.066 & 14.27 & 0.715 \\ \text { AOIJ } & 0.871 & 0.752 & 0.069 & 12.62 & 0.566 \\ \text { AOIH } & & & & & \\ \text { Socio-economic and } & & & & & 0.635 \\ \text { political (SEP) } & 1.000 & 0.797 & \mathrm{f} & - & 0.638 \\ \text { SEPC } & 0.978 & 0.781 & 0.087 & 11.25 & 0.639 \\ \text { SEPA } & 0.862 & 0.789 & 0.097 & 8.89 & 0.623 \\ \text { SEPE } & & & & & \\ \text { Alternate fuels and } & & 0.800 & \mathrm{f} & - & 0.641 \\ \text { fuel properties (AF) } & & & 0.118 & 7.93 & 0.617 \\ \text { AFA } & 1.000 & 0.785 & & & \end{array}$

Note: $\mathrm{f}=$ Indicates a parameter fixed at 1.0 in the original solution

Table 4: Reliability, validity, and correlations of AT, AOI, SEP, and AF constructs

\begin{tabular}{lrrrrrrrr}
\hline & CR $^{\mathrm{a}}$ & \multicolumn{1}{c}{ AVE $^{\mathrm{b}}$} & \multicolumn{1}{l}{ MSV } & ASV & AOI & AT & AF & SEP \\
\hline AOI & 0.877 & 0.557 & 0.251 & 0.165 & 0.746 & & & \\
AT & 0.915 & 0.612 & 0.251 & 0.198 & 0.500 & 0.782 & & \\
AF & 0.715 & 0.513 & 0.183 & 0.118 & 0.397 & 0.367 & 0.716 & \\
SEP & 0.781 & 0.505 & 0.185 & 0.087 & 0.246 & 0.422 & 0.116 & 0.704 \\
\hline
\end{tabular}

Note; For Composite reliability $(\mathrm{CR}>.70)$; Convergent validity $(\mathrm{CR}>\mathrm{AVE}>.50)$;

Discriminate validity (MSV $<$ AVE) $\mathrm{MSV}=$ Maximum shared variance; $\mathrm{ASV}=$ Average shared variance (Hair et al. 2010)

Table 5: AMOS output -Covariance's: (Group number 1 - Default model)

\begin{tabular}{llrlll}
\hline & & Estimate & S.E. & C.R. & P \\
\cline { 2 - 6 } AT $<-->$ & AF & .179 & .040 & 4.419 & $* * *$ par_18 \\
AOI <--> & AT & .299 & .049 & 6.041 & $* * *$ par_19 \\
SEP <--> & AOI & .165 & .051 & 3.213 & .001 par_20 \\
SEP <--> & AF & .064 & .045 & 1.406 & .160 par_21 \\
SEP <--> & AT & .282 & .055 & 5.097 & $* * *$ par_22 \\
AOI <--> & AF & .195 & .043 & 4.568 & $* * *$ par_26 \\
\hline
\end{tabular}

\subsection{Structural equation model}

For the structural equation model, the maximum likelihood estimation and covariance matrix and 17 scale items were considered as input. The structural model with four latent factors is shown in Figure 3. The results of the hypothesis testing showed a good fit between the model and the data (Table 6). The ratio of $\chi^{2}$ over the degree of 
freedom (df) has been suggested as the best measure of goodness-of-fit (Hair et al., 2010), which should be $<3$. The $\chi^{2} / \mathrm{DF}$ ratio of our developed model was 1.123 . The $p$ value $=0.188$ is also significant (Hair et al. 2010). According to Singh et al. (2016), GFI should be higher than 0.80 . GFI and AGFI had the values 0.950 and 0.925 , which were well within the limits as given by Byrne (2013) and Singh et al. (2016). NFI and CFI were also used to examine the supreme (Byrne, 2013; Singh and Sharma, 2016). The values of NFI and CFI were 0.961 and 0.996 respectively, which indicated a well-fitted model. TLI, RMR, and RMSEA were also within the limits as given by Hair at al. (2010) and Joreskog and Sorbom (1988) and thus met the criteria of an acceptable model.

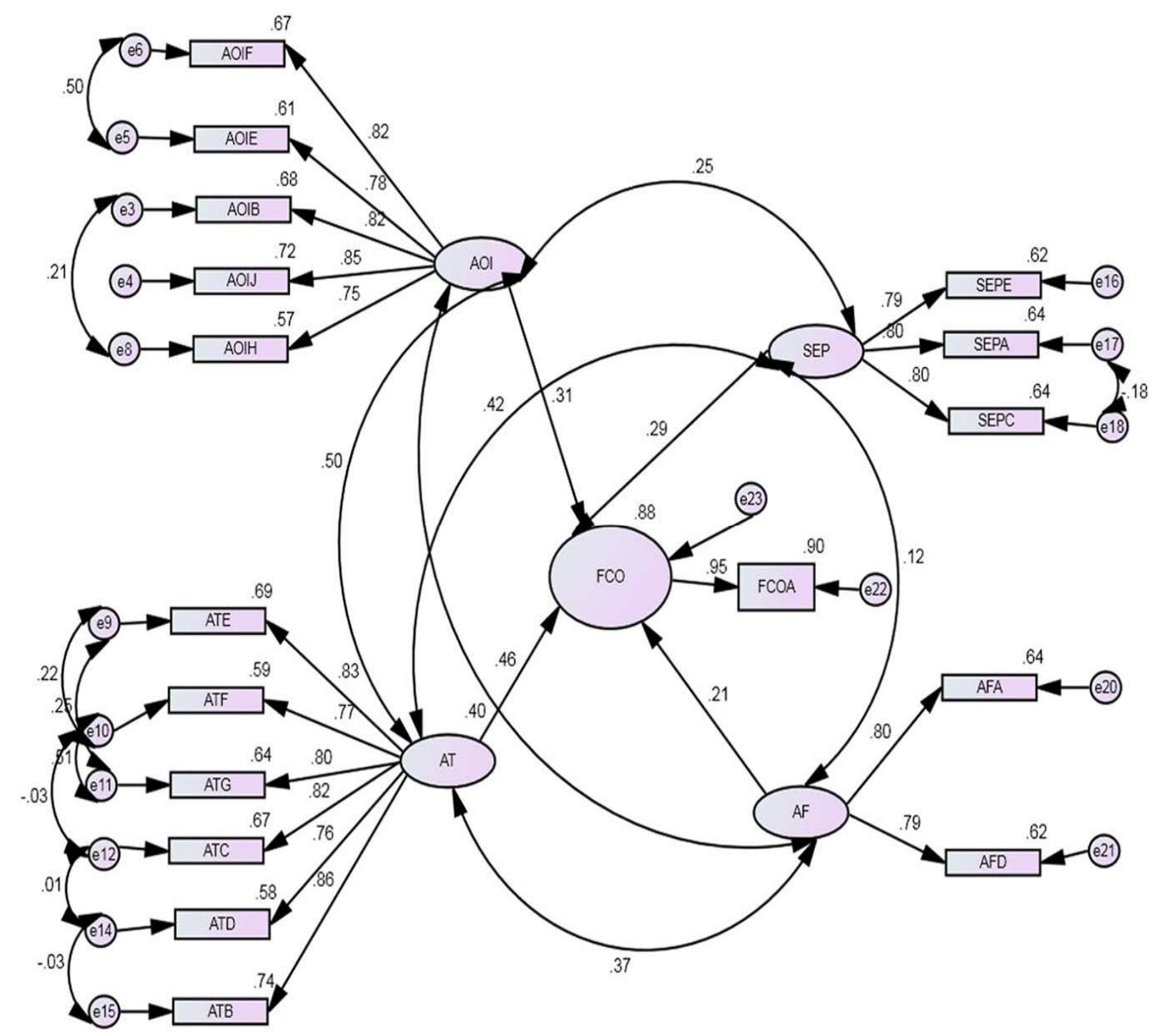

Figure 3: Structural model of FCO

Table 6 and Figure 3 show the results of path coefficients with FCO. For H1, AT has a noteworthy and optimistic influence on the FCO. The result presented in Table 6 and Figure 3 indicates that $\mathrm{H} 1$ is intensely influenced by the path coefficient of $\beta=0.463$ significantly $(p<0.001)$ and AT has a stronger influence on FCO as contrasted to the other factors. In the second hypothesis $\mathrm{H} 2$, it is hypothesised that AOI has a substantial and positive impression on FCO. Therefore, $\mathrm{H} 2$ is supported $(\beta=0.311 ; p<0.001)$. H3 suggests that the SEP has a significant positive influence on FCO, which is supported by $\beta=0.292 ; p<0.001$. H4 implies that the AF has a positive significant impact on FCO, which is supported by $\beta=0.214 ; p<0.001$. Also, Figure 3 shows the correlation among 
the all the constructs of FCO, which are as AT $<->$ AOI (0.500), SEP $<->$ AT (0.422), AOI $<->$ AF (0.397), AT $<->$ AF (0.367), SEP $<->$ AOI (.246) and SEP $<->$ AF (0.116).

Table 6: Fit indices of structural model results

\begin{tabular}{lllll}
\hline $\begin{array}{l}\text { Path coefficients of ERP model } \\
\text { Relationship }\end{array}$ & $\begin{array}{l}\text { Standard path } \\
\text { Coefficients }\end{array}$ & C.R. & $\begin{array}{l}\text { p- } \\
\text { values }\end{array}$ & $\begin{array}{l}\text { Support of } \\
\text { hypothesis }\end{array}$ \\
\hline $\mathrm{AT} \rightarrow$ FCO & 0.463 & 3.651 & 0.001 & H1 Supported \\
$\mathrm{AOI} \rightarrow$ FCO & 0.311 & 3.311 & 0.001 & H2 Supported \\
$\mathrm{SEP} \rightarrow$ FCO & 0.292 & 3.594 & 0.001 & H3 Supported \\
$\mathrm{AF} \rightarrow$ FCO & 0.214 & 3.460 & 0.001 & H4 Supported \\
\hline The goodness of fit indices & Criteria & & Indicators \\
for FLOAT model & & & \\
$\chi^{2}$ test & & & \\
$\chi^{2}$ & 113.409 & & \\
$\chi^{2} / \mathrm{DF}$ & $1<\chi^{2} / \mathrm{DF}<3$ & & \\
Fit indices & & & \\
GFI & $>0.90$ & 0.950 & \\
AGFI & $>0.90$ & 0.925 & \\
NFI & $>0.90$ & 0.961 & \\
RMR & $\leq 0.08$ & 0.025 & \\
CFI & $>0.90$ & 0.996 & \\
TLI & $>0.90$ & 0.994 & \\
RMSEA & $<0.05$ good fit & 0.022 & \\
& $<0.08$ acceptable fit & & \\
\hline NOte: & & & & \\
\end{tabular}

Note: $\mathrm{f}=$ Indicates a parameter fixed at 1.0 in the original solution

\subsection{Genetic algorithm}

In the simulation, for every run the parameters utilised were population size $=200$, crossover probability $=0.90$, mutation probability $=0.1$, elitisms $=1$, termination criteria $=300$ trials, epsilon $=0.0001$ and maximum generations $=300$. The model was ran with 12 AT variables: wing span, wing aspect ratio, wing taper ratio, fuselage length and diameter, and horizontal tail aspect ratio, horizontal tail area, vertical tail aspect ratio and engine thrust for optimisation, three constraints, and 14 additional constants. The model was compared with the study by Singh (2018) and the well-known conformation of various transport aircrafts. The actual maximum take-off weight value and the calculated value were quite close. After validating the model, simulations were carried out to find the optimised values of decision variables. The corresponding value of maximum take-off weight was $71,678 \mathrm{~kg}$. The GA model was then tested for 100 runs and the mean value of the take-off weight was estimated. The average value of maximum take-off weight after 50 runs was $71,689 \mathrm{~kg}$. Figure 4 shows the finest and mean fitness vs. maximum take-off weight. In addition, Table 7 shows the FCO results for mid-range transport aircraft. Further, the fuel consumption for the calculated parameters (Singh, 2018) using Equation 1 was 2.04 litres per 100 kilometres, while the value of fuel consumption using the developed model values was 2.02 litres per 100 kilometres. So, the value of the fuel consumption of this study for a medium-haul flight was improved by 0.02 litres per 100 kilometres. 


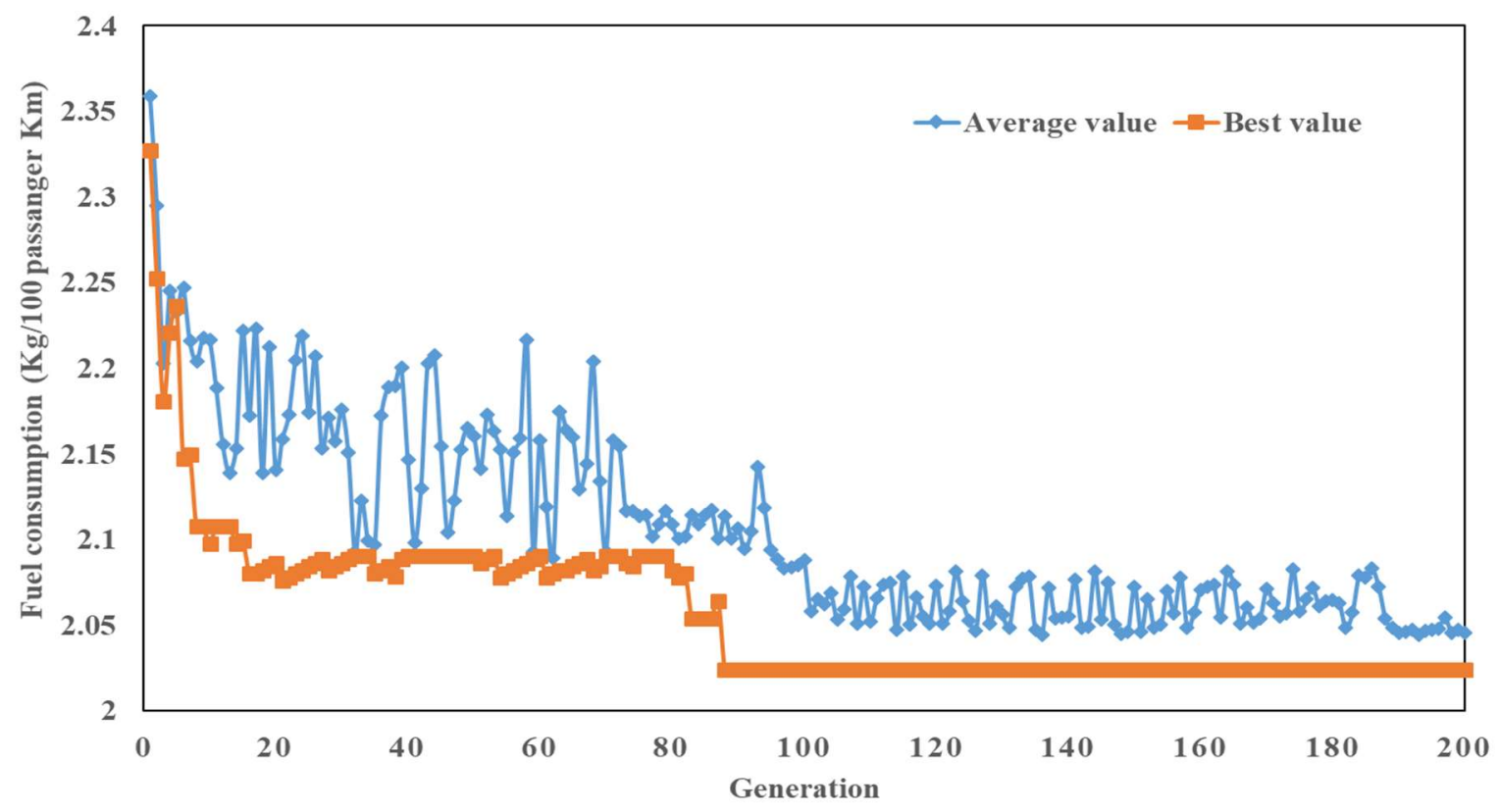

Figure 4: Best and average Fitness (kg/100 passenger km) vs generation

Table 7: FCO results of mid-range transport aircraft

\begin{tabular}{|c|c|c|c|}
\hline Variable & $\begin{array}{l}\text { Optimized } \\
\text { values } \\
\text { Developed } \\
\text { model }\end{array}$ & $\begin{array}{l}\text { Optimized values } \\
\text { from } \\
\text { Singh (2018) }\end{array}$ & $\begin{array}{c}\text { Gains } \\
(\%)\end{array}$ \\
\hline $\begin{array}{l}\text { Fuel consumption }(\mathrm{kg} / 100 \\
\text { passenger } \mathrm{km})\end{array}$ & 2.01 & 2.04 & -1.47 \\
\hline Maximum takeoff weight $(\mathrm{kg})$ & 71,689 & 71,745 & -0.08 \\
\hline Wing span (m) & 34.34 & 34.21 & 0.38 \\
\hline Wing aspect ratio & 9.81 & 9.62 & 1.98 \\
\hline Wing area $\left(\mathrm{m}^{2}\right)$ & 121.92 & 121.66 & 0.21 \\
\hline Horizontal tail area $\left(\mathrm{m}^{2}\right)$ & 22.69 & 23.17 & -2.07 \\
\hline Vertical tail area $\left(\mathrm{m}^{2}\right)$ & 17.73 & 18.06 & -1.83 \\
\hline Fuselage length (m) & 37.01 & 37.06 & -0.13 \\
\hline Fuselage diameter $(\mathrm{m})$ & 3.60 & 3.68 & -2.17 \\
\hline Engine thrust (KN) & 113.92 & 114.16 & -0.21 \\
\hline $\begin{array}{l}\text { Thrust specific fuel } \\
\text { consumption }(1 / \mathrm{s})\end{array}$ & 0.00017 & 0.00018 & -5.56 \\
\hline Rate of descent (ft/min) & 1,321 & 1,280 & 3.20 \\
\hline Takeoff field length (m) & 2,027 & 2,075 & -2.31 \\
\hline Operating empty weight $(\mathrm{kg})$ & 38,312 & 38,458 & -0.38 \\
\hline Lift to drag ratio & 18.8 & 18.7 & 0.53 \\
\hline Fuel weight (kg) & 15,540 & 15,632 & -0.59 \\
\hline
\end{tabular}




\section{Discussion, conclusions and future research}

Some airlines have realised the importance of implementing a FCO programme in reducing operating cost and environmental impact of an aircraft but due to absence of the factors that establish a comprehensive set of FCO it has not been possible. This study offers some useful guidelines to analyse their search for fuel consumption reduction. The results show that the proposed model of FCO is validated for a substantial descriptive and forecasting power. Thus, the incorporation of AT, AOI, SEP and AF factors with FCO is both hypothetically appealing as well empirically significant. Also, in this study evolutionary genetic algorithm was used for FCO, in which numerical optimisation programme was developed for a medium-haul aircraft using MATLAB. It could be extended to any other aircraft. With such a decision tool, savings in fuel are possible and the efficiency of aviation systems can be improved. This would further reduce the environmental impact of the aviation sector.

Based on a review of the existing literature on $\mathrm{FCO}$, four dimensions having a significant impact on aviation fuel consumption were identified; namely AT, AOI, SEP and AF. Our hypotheses development includes these four constructs. The conceptual framework showed that AT, AOI, SEP and AF, all of which were posited as predictor variables with FCO as the dependent variable, have a positive and direct effect on FCO. Briefly, the hypothesis development evolved four path hypotheses $(\mathrm{H} 1, \mathrm{H} 2, \mathrm{H} 3, \mathrm{H} 4)$ for these four influencing factors and FCO. The study showed that FCO in aviation industry is influenced by these four critical factors.

Among these four constructs for ERP, AT $(\beta=0.463 ; p<0.001)$ shows the strongest influence on FCO, followed by AOI $(\beta=0.311 ; p<0.001)$, SEP $(\beta=0.292 ; p<0.001)$ and AF $(\beta=0.214 ; p<0.001$. The highest correlation was observed (Figure 3$)$ between AT $<->$ AOI (0.500) followed by SEP $<->$ AT (0.422), AOI $<->$ AF (0.367), AT $<-$ $>$ AF (0.367), SEP $<->$ AOI (0.246) and SEP $<->$ AF (0.116).

AT is the key factor for aviation FCO. Fuel efficiency comes from improvement in technology and designing. ATB, ATC, ATD, ATE, ATF and ATG are the six important dimensions that contributing to AT and are evolved as essential components for FCO. From evaluating these factors, it can be concluded that AT depends on the propulsive, structural, and aerodynamic efficiency and is the strongest factor for aviation FCO. In addition, the key technologies for FCO consists of light-weight airframes, efficient engines and aerodynamically improved body and wings.

Five dimensions for AOI - AOIB, AOIE, AOIF, AOIH and AOIJ - were evolved in the final structural model (Figure 3). The objective of AOI is to explore aspects related with aircraft operations and infrastructure, which are of utmost importance in ensuring FCO. The study of these seven dimensions of AOI indicates that to ensure FCO, operations of an aircraft in infrastructural conditions like terminal airspace design, runway and altitude must be mutually compatible. A better payload factor, optimised cruise speed and refined air traffic management offer the best instant ways to reduce the environmental impact of aviation.

SEP can be strengthened by effective strategic planning. Considering fuel prices, community awareness and taxes and charges is necessary to work on FCO. To accelerate technological and operational innovations that reduce the aviation fuel consumption, we must better understand the effect of higher fuel consumption, and scientific knowledge, public awareness, and government regulations about the impacts of higher aviation fuel consumption should be higher for faster improvement of the FCO in aviation.

AF consists of two dimensions AFA and AFD. The information on alternative fuels 
and fuel properties create the criteria for selecting right and compatible fuel for a specific aircraft to control fuel consumption. Based on the examination of AF for FCO in aviation, environmental impact of aviation can be decreased by using biofuel in future. AF could also minimise greenhouse emissions from air transport as development in their feedstock could eliminate $\mathrm{CO}_{2}$ from the atmosphere. But, a solid understanding of the FCO in aviation is still needed. In addition to aircraft technology improvements, improvements in air traffic management and operations, effective and supportive socioeconomic and policy measures and substitution of fossil fuel with bioenergy from regenerative sources can together make this difficult task achievable.

Penner (1999) predicts almost 40\% reduction in fuel consumption with the use of new aircraft technology by 2050 and $8 \%$ to $18 \%$ by updated airplanes and their operability. In addition, IEA (2009) and IATA (2013) predict 50\% fuel burn decrease potential with the use of superiority technology by 2050 and $8 \%$ to $18 \%$ through enhanced AOI. These studies provide evidence to support the hypotheses and hierarchy of the factors for FCO. Also, the highest correlation between AT $<\rightarrow$ AOI showed that there exists a higher FCO in between these factors. Lee et al. (2001), Singh (2016), and Singh et al. (2016) support the evidence of highest correlation between aircraft technology and operability.

As shown in Table 7, reduction of $0.6 \%$ in fuel consumption per 100 passengers' kilometre was obtained, while all conditions were met. The reduction was achieved through modified wingspan and wing aspect ratio and reduced maximum take-off weight. Sometimes, a small population causes the GA to rapidly converge on a local minimum because it inadequately samples the parameter space. Elitism was employed to avoid missing a potentially best solution by making it certain that its occurrence was preserved in the population at every generation until a better solution was found.

Moreover, examinations from the two runs conducted with and without elitism show that elitism leads to a more rapid solution with slightly higher fitness. Specifically, the analysed learning proves that using an evolutionary optimisation algorithm is helpful in evaluating possible expansions in aircraft fuel utilisation as well as in introductory designing. Also, the optimisation performed with a MATLAB-coded GA has given better outcomes than a spreadsheet-coded GA. By optimising the fuel consumption of transport aircrafts, efficiency and productivity of the aviation sector could be enhanced.

Future studies can include additional variables not incorporated in this study. Also, both SEP and AF were not included in the optimisation model and future studies can consider them in the optimisation process. Furthermore, about $66 \%$ of the sample was drawn from academics and researchers; in future, the sample size can be improved upon for a more aviation industry-specific model of FCO. Besides, we can use innovative techniques such as hybrid algorithm, ant colony optimisation, bee colony and optimisation techniques, and real-coded GA approach for FCO. In this study, only fuel consumption was optimised; however, in future, lift-over-drag and maximum aircraft take-off weight can also be attempted for simultaneous optimised.

\section{References}

Anderson, J.C. and Gerbing, D.W., (1988) "Structural equation modeling in practice: A review and recommended two-step approach", Psychological Bulletin, 103(3), p.411.

Antoine, N.E. and Kroo, I.M., (2005) "Framework for aircraft conceptual design and environmental performance studies", AIAA Journal, 43(10), pp.2100-2109. 
Babikian, R., Lukachko, S. P., and Waitz, I. A., (2002), “The historical fuel efficiency characteristics of regional aircraft from technological, operational, and cost perspectives", Journal of Air Transport Management, 8(6), 389-400.

Binitha, S., and Sathya, S. S. (2012), "A survey of bio inspired optimization algorithms", International Journal of Soft Computing and Engineering 2(2):137-151.

Bollen, K.A., (1989), Structural equations with Latent Variables, Wiley-Interscience Publication.

Brueckner, J. K., and Zhang, A. (2010), Airline emission charges: Effects on airfares, service quality, and aircraft design, Transportation Research Part B: Methodological, 44(8), 960-971.

Byrne, B. M. (2013). Structural equation modeling with AMOS: Basic concepts, applications, and programming, Routledge.

Camp, C., Pezeshk, S., and Cao, G. (1998), "Optimized design of two-dimensional structures using a genetic algorithm" Journal of Structural Engineering 124(5): 551559.

Chaudhry, Ali I., and Ahmed A. (2014), "Preliminary aircraft design optimization using genetic algorithms", Journal of Scientific and Industrial Research 73:302-307.

Chen, F. Y. (2013), "The intention and determining factors for airline passengers' participation in carbon offset schemes", Journal of Air Transport Management, 29, 1722.

Churchill, G.A., (1979), “A paradigm for developing better measures of marketing constructs", Journal of Marketing Research 16, pp. 64-73.

Coakes, S. J., and Steed, L. (2009), SPSS: Analysis without anguish using SPSS version 14.0 for Windows, John Wiley and Sons, Inc.

Corporan, E., Edwards, T., Shafer, L., DeWitt, M. J., Klingshirn, C., Zabarnick, S., and Klein, J. (2011), Chemical, thermal stability, seal swell, and emissions studies of alternative jet fuels. Energy and Fuels, 25(3), 955-966.

Cortina, J. M. (1993), "What is coefficient alpha? An examination of theory and applications" Journal of Applied Psychology, 78(1), 98.

Deb, K., Pratap, A., Agarwal, S., and Meyarivan, T. A. M. T. (2002), “A fast and elitist multi-objective genetic algorithm: NSGA-II. Evolutionary Computation, IEEE Transactions 6(2): 182-197.

Fornell, C., and Larcker, D. F. (1981), "Evaluating structural equation models with unobservable variables and measurement error, Journal of Marketing Research, 39-50.

Gen, M., and Cheng, R. (1996), "A survey of penalty techniques in genetic algorithms, In Evolutionary Computation, Proceedings of IEEE International Conference on 804809.

Green, J. E., (2009), "The potential for reducing the impact of aviation on climate", Technology Analysis and Strategic Management 21(1): 39-59.

Hair, J.F., Black, W.C., Babin, B.J., and Anderson, R.E. (2010), "Multivariate Data Analysis, 7th edition" Pearson Education, Inc.

Henderson, R. P., Martins, J. R. R. A., and Perez, R. E. (2012), “Aircraft conceptual design for optimal environmental performance", Aeronautical Journal 116(1175): 1. 
Hihara, K. (2011), "Analysis on bargaining about global climate change mitigation in international aviation sector", Transportation Research Part E: Logistics and Transportation Review, 47(3), 342-358.

Hileman, J. I., De la Rosa Blanco, E., Bonnefoy, P. A., and Carter, N. A. (2013), "The carbon dioxide challenge facing aviation, Progress in Aerospace Sciences, 63, 84-95.

International Air Transport Association (IATA), (2013), “Technology Roadmap Report, 4th edition.

International Energy Agency (IEA), (2009), Transport energy and CO2. IEA/OECD.

IPCC, (2018), "Summary for Policymakers. In: Global Warming of $1.5^{\circ} \mathrm{C}$. An IPCC Special Report on the impacts of global warming of $1.5^{\circ} \mathrm{C}$ above pre-industrial levels and related global greenhouse gas emission pathways, in the context of strengthening the global response to the threat of climate change, sustainable development, and efforts to eradicate poverty, pp 32.

Janic, M. (2010), "Is liquid hydrogen a solution for mitigating air pollution by airports?" International Journal of Hydrogen Energy, 35(5), 2190-2202.

Joreskog, K. G. and Sorbom, D. (1988). A Guide to the Program and Applications, Chicago: SPSS, Inc.

Kachitvichyanukul, V. (2012.), "Comparison of Three Evolutionary Algorithms, Industrial Engineering and Management Systems 11(3): 215-223.

Kar, R. (2010), Dynamics of implementation of mitigating measures to reduce CO2 emissions from commercial aviation (Doctoral dissertation, Massachusetts Institute of Technology).

Kline, Rex B. (2012), Principles and practice of structural equation modeling, The Guilford Press, New York London.

Kundu, A. K. (2010), Aircraft designs, Cambridge University Press. Vol. 27.

Lawrence, P. (2009), "Meeting the challenge of aviation emissions: an aircraft industry perspective" Technology Analysis and Strategic Management, 21(1), 79-92.

Lee, D.S., Pitari, G., Grewe, V., Gierens, K., Penner, J.E., Petzold, A., Prather, M.J., Schumann, U., Bais, A., Berntsen, T. and Iachetti, D., 2010. Transport impacts on atmosphere and climate: Aviation. Atmospheric Environment, 44(37), pp.4678-4734.

Lee J. J., Stephen P. Lukachko, Ian A. Waitz and Andreas Schafer, (2001), "Historical and future trends in aircraft performance cost and emission". Annual Review Energy Environment, 26, 167-200.

Lee, J., and Mo, J. (2011), “Analysis of Technological Innovation and Environmental Performance Improvement in Aviation Sector. International Journal of Environmental Research and Public Health, 8(9), 3777-3795.

Lu, C. S., Lai, K. H., and Cheng, T. E. (2007), “Application of structural equation modeling to evaluate the intention of shippers to use Internet services in liner shipping" European Journal of Operational Research, 180(2), 845-867.

Mclntosh, A. R., and Gonzalez-Lima, F. (1994), "Structural equation modeling and its application to network analysis in functional brain imaging". Human Brain Mapping, 2(1-2), 2-22.

Miller, B., Minogue, K., and Clark, J. P. (2001), "Constraints in aviation infrastructure and surface aircraft emissions". Massachusetts Institute of Technology, pp-1-15. 
Nojoumi, H., Dincer, I., and Naterer, G. F. (2009), "Greenhouse gas emissions assessment of hydrogen and kerosene-fueled aircraft propulsion", International Journal of Hydrogen Energy, 34(3), 1363-1369.

Penner, J. E. (Ed.) (1999), "Aviation and the global atmosphere: a special report of IPCC Working Groups I and III in collaboration with the Scientific Assessment Panel to the Montreal Protocol on Substances that Deplete the Ozone Layer", Cambridge University Press.

Raymer, D. P. (1999), “Aircraft Design: A Conceptual Approach, American Institute of Aeronautics and Astronautics" Inc., Reston, VA.

Sadraey, M. H. (2012), Aircraft design: A systems engineering approach, John Wiley and Sons.

Senzig, D. A., Fleming, G. G., and Iovinelli, R. J. (2009), "Modeling of terminal-area airplane fuel consumption, Journal of Aircraft, 46(4), 1089-1093.

Simões, A. F., and Schaeffer, R. (2005), "The Brazilian air transportation sector in the context of global climate change: $\mathrm{CO} 2$ emissions and mitigation alternatives", Energy conversion and management, 46(4), 501-513.

Singh, V. (2018), "Fuel consumption minimization of transport aircraft using real-coded genetic algorithm”, Proc IMechE Part G: J Aerospace Engineering, Vol. 232 (10), 1925-1943.

Singh, V., (2016). Perceptions of emission reduction potential in air transport: A structural equations modelling approach. Environmental Systems \& Decision, 36(4), 377-403.

Singh, V., Chauhan, S. C, and Tejyan S., (2016), "Greenhouse Gas Emission Reduction Potentials in Air Transport: A Structural Equation Modelling-Based Multi-Group Analysis. Technology Analysis and Strategic Management, Vol. 29, No. 4, 442-461.

Singh, V., and Sharma, S. K. (2016), "Analyzing the moderating effects of respondent type and experience on the fuel efficiency improvement in air transport using structural equation modeling, European Transport Research Review, 8(2), 1-20.

Singh, V., and Sharma, S. K. (2015). "Fuel consumption optimization in air transport: a review, classification, critique, simple meta-analysis, and future research implications", European Transport Research Review, 7(2), 1-24.

Singh, V., and Sharma, S. K. (2014), "Evolving base for the fuel consumption optimization in Indian air transport: application of structural equation modeling", European Transport Research Review, 6(3), 315-332.

Singh, V., Sharma, S. K., and Vaibhav, S. (2016), "Transport aircraft conceptual design optimization using real coded genetic algorithm", International Journal of Aerospace Engineering, 2016 (2016), 11 pages, Article ID 2813541.

Sgouridis, S., Bonnefoy, P. A., and Hansman, R. J. (2011), “Air transportation in a carbon constrained world: Long-term dynamics of policies and strategies for mitigating the carbon footprint of commercial aviation", Transportation Research Part A: Policy and Practice, 45(10), 1077-1091.

Sivanandam, S. N., and Deepa, S. N. (2007), "Introduction to genetic algorithms" Springer Science and Business Media.

Stewart, D. W. (1981), "The application and misapplication of factor analysis in marketing research", Journal of Marketing Research, 51-62. 
Vespermann, J., and Wald, A. (2011), "Much Ado about Nothing? -An analysis of economic impacts and ecologic effects of the EU-emission trading scheme in the aviation industry", Transportation Research Part A: Policy and Practice, 45(10), 1066-1076.

Wang, Y., Yin, H., Zhang, S., and Yu, X. (2014), "Multi-objective optimization of aircraft design for emission and cost reductions", Chinese Journal of Aeronautics, 27(1), 5258.

Worthington, R. L., and Whittaker, T. A. (2006), "Scale development research a content analysis and recommendations for best practices", The Counseling Psychologist, 34(6), 806-838.

Yamaguchi, K. (2010), "Voluntary CO2 emissions reduction scheme: Analysis of airline voluntary plan in Japan", Transportation Research Part D: Transport and Environment, 15(1), 46-50.

\section{Appendix A: Scale item used in the study}

\begin{tabular}{|c|c|}
\hline Construct & Item and their abbreviation \\
\hline \multirow[t]{8}{*}{ Aircraft technology and design (AT) } & 1. Engine type (ATA) \\
\hline & 2. Lift/drag (ATB) \\
\hline & 3. Operating specific fuel consumption (ATC) \\
\hline & 4. Wing span (ATD) \\
\hline & 5. Structural weight (ATE) \\
\hline & 6. Engine thrust (ATF) \\
\hline & 7. Aircraft maximum design speed (ATG) \\
\hline & 8. Aircraft Centre of gravity position (ATF) \\
\hline \multirow[t]{10}{*}{ Aviation operations and infrastructure (AOI) } & 9. Takeoff filed length (AOIA) \\
\hline & 10. Fuel weight (AOIB) \\
\hline & 11. Weather conditions (AOIC) \\
\hline & 12. Reserve fuel weight (AOID) \\
\hline & 13. Payload weight (AOIE) \\
\hline & 14. Stage length (AOIF) \\
\hline & 15. Landing field length (AOIG) \\
\hline & 16. Mach number $(\mathrm{AOIH})$ \\
\hline & 17. Flight profile (AOII) \\
\hline & 18. Crew weight (AOIJ) \\
\hline \multirow[t]{6}{*}{ Socio-economic and policy measure (SEP) } & 19. Fuel prices (SEPA) \\
\hline & 20. Economic incentives (SEPB) \\
\hline & 21. Community awareness (SEPC) \\
\hline & 22. Voluntary measures (SEPD) \\
\hline & 23. Charges and taxes (SEPE) \\
\hline & 24. Emission trading scheme (SEPF) \\
\hline \multirow{5}{*}{$\begin{array}{l}\text { Aviation alternative fuels and fuels } \\
\text { properties (AF) }\end{array}$} & 25. Alternative fuel type (AFA) \\
\hline & 26. Fuel availability (AFB) \\
\hline & 27. Flash point (AFC) \\
\hline & 28. Calorific value of fuel (AFD) \\
\hline & 29. Smoke point (AFE) \\
\hline Fuel consumption optimization (FCO) & $\begin{array}{l}\text { 30. Fuel consumption optimization measuring instrument } \\
\text { (FCOA) }\end{array}$ \\
\hline
\end{tabular}

